\title{
Lung abscess complicating chondromas in Carney's syndrome
}

\author{
R.P. Convery*, A.J. Grainger**, N.K. Bhatnagar+, D. Scott***, S.J. Bourke*
}

\begin{abstract}
Lung abscess complicating chondromas in Carney's syndrome. R.P. Convery, A.J. Grainger, N.K. Bhatnagar, D. Scott, S.J. Bourke. CERS Journals Ltd 1998.

ABSTRACT: Carney's syndrome consists of a combination of three rare tumours: gastric leiomyosarcoma, pulmonary chondroma and catecholamine-secreting paraganglioma.

We describe a young woman with Carney's syndrome, who developed a lung abscess, due to obstruction of a bronchus by a chondroma, 11 yrs after having had a partial gastrectomy for a leiomyosarcoma.

Eur Respir J 1998; 11: 1409-1411.
\end{abstract}

In 1977, CARNeY et al. [1] described an unusual syndrome characterized by the concomitant or successive occurrence of a combination of three disparate tumours in young females: gastric leiomyosarcoma, pulmonary chondroma and catecholamine-secreting paraganglioma. The pulmonary chondromas may be multiple and bilateral, and are often found as incidental lesions on chest radiography during investigation of other components of the syndrome [1-10]. They tend to grow slowly over many years, but are benign and do not usually give rise to complications. We describe a case of Carney's syndrome, in which the chondromas were complicated by the development of a lung abscess requiring surgical resection.

\section{Case report}

A 26 yr old female presented with a 3-week history of right pleuritic pain, sweating and rigors. She had a pyrexia of $38.5^{\circ} \mathrm{C}$ and crackles were audible over the right chest posteriorly. Chest radiography showed a nodule in the right upper lobe and a cavitating lesion with an air-fluid level in the apical segment of the right lower lobe distal to a lobulated mass (fig. 1). Computed tomography (CT) demonstrated a further nodule in the left lower lobe and showed that the nodules were solid, well-circumscribed lesions containing a rim of calcification (fig. 2). Eleven years previously, the patient had undergone a partial gastrectomy for a malignant leiomyosarcoma of the stomach, having presented with anaemia of $35 \mathrm{~g} \cdot \mathrm{L}^{-1}$. A chest radiograph at that time was normal.

Investigations showed: a white cell count of $21.2 \times 10^{9}$ cells $\cdot \mathrm{L}^{-1}$ (95\% neutrophils); haemoglobin level of $77 \mathrm{~g} \cdot \mathrm{L}^{-1}$; and erythrocyte sedimentation rate of $105 \mathrm{~mm}$ in the first hour. Bronchoscopy revealed extrinsic compression of the posterior wall of bronchus intermedius, and transbronchial
Depts of *Respiratory Medicine, **Radiology and ***Pathology, Royal Victoria Infirmary, Newcastle upon Tyne, UK. ${ }^{+}$Cardiothoracic Centre, Freeman Hospital, Newcastle upon Tyne, UK.

Correspondence: S.J. Bourke, Dept of Respiratory Medicine, Royal Victoria Infirmary, Newcastle upon Tyne, NE1 4LP, UK Fax: 1912275224

Keywords: Carney's syndrome, leiomyosarcoma, paraganglioma, pulmonary chondroma

Received: June 51997

Accepted after revision January 51998

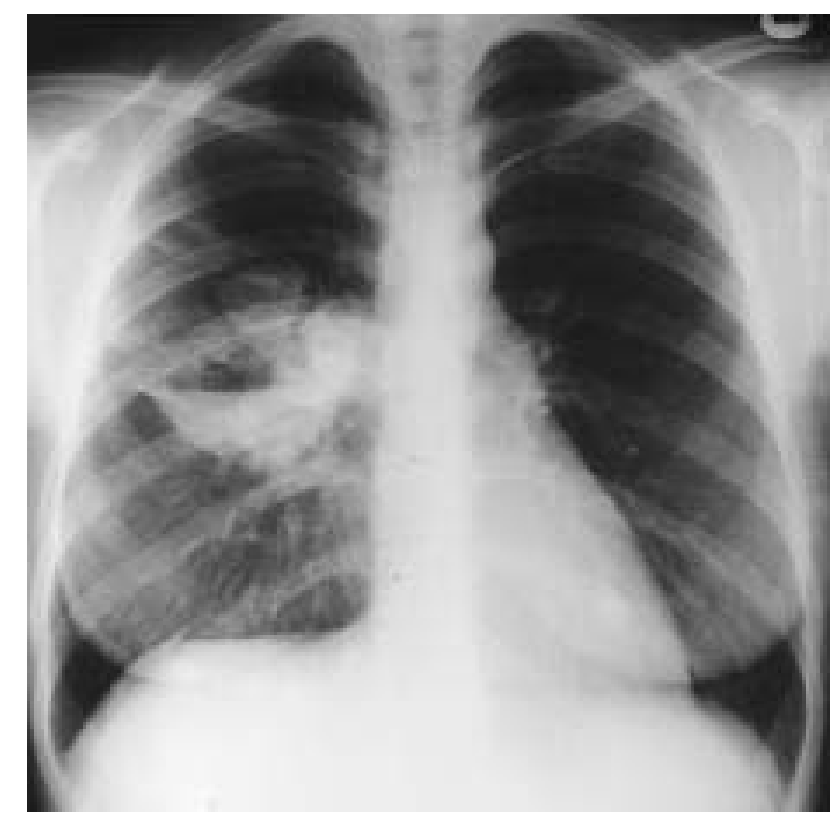

Fig. 1. - Chest radiograph showing a cavity with an air-fluid level in the apical segment of the right lower lobe, a lobulated mass projected over the right hilum, and a well-defined round mass in the right upper lobe.

biopsies from the apical segment of the right lower lobe showed groups of chondrocytes and chondroid matrix indicative of a chondroma, with no evidence of malignancy (fig. 3). Transthoracic needle aspiration of the cavitating lesion yielded pus, but no organisms were isolated on culture. On upper gastointestinal endoscopy, there was no evidence of recurrence of the leiomyosarcoma. Urinary catecholamine levels were normal, and CT and an iodine-131 metaiodobenzylguanidine (MIBG) scan produced no evidence of a paraganglioma. The patient's blood group was 


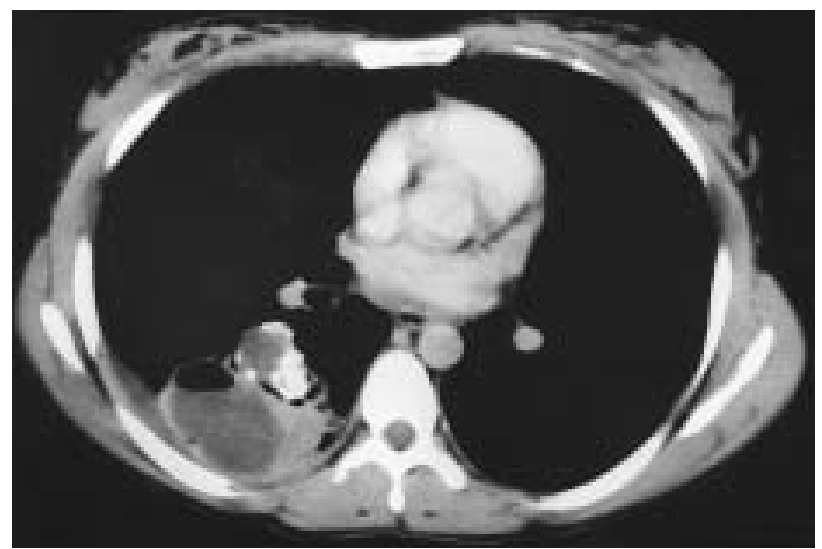

Fig. 2. - Contrast enhanced axial computed tomographic scan showing the cavitating lesion with an air-fluid level lying distal to a lobulated mass, which has a rim of calcification.

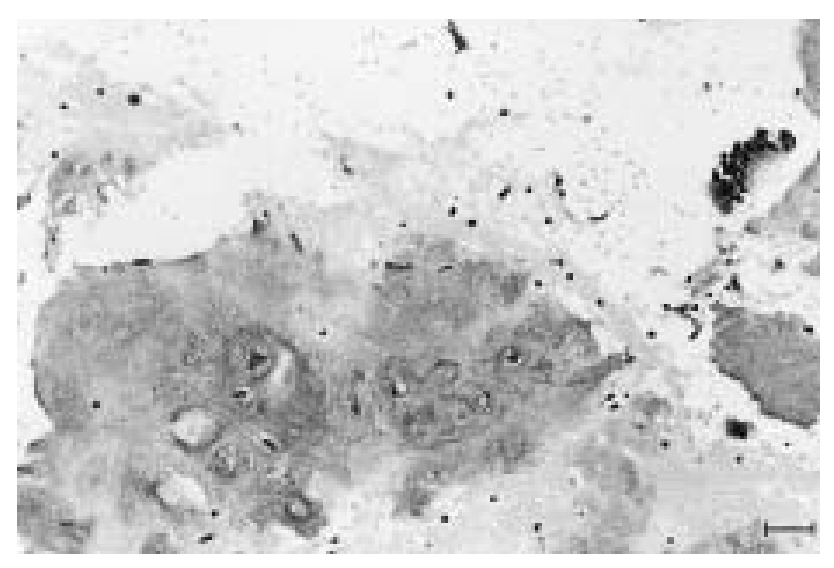

Fig. 3. - Transbronchial biopsy containing lobules of cartilaginous matrix with chondrocytes and fragments of respiratory epithelium. (Haematoxylin and eosin stain; internal scale bar $=75 \mu \mathrm{m}$ ).

O-positive, tissue type was HLA A1, A11, B7, B37, DR15, and chromosomal analysis showed a normal 46XX karyotype.

A diagnosis of incomplete Carney's syndrome was made on the basis of the histologically proven gastric leiomyosarcoma and pulmonary chondroma. Although the patient's symptoms improved on antibiotics, it was thought that the abscess cavity would not resolve unless the chondroma obstructing the apical segment of the right lower lobe was removed. A right thoracotomy was performed and a $9 \times 5 \mathrm{~cm}$ lobulated chondroma in the apical segment of the right lower lobe and a $3 \times 2 \mathrm{~cm}$ chondroma in the right upper lobe were enucleated, with conservation of the surrounding lung tissue. Histology confirmed benign chondroma and stains for oestrogen receptors were negative.

The patient is being kept under long-term follow-up to monitor the residual left lower lobe chondroma and to watch for the potential future development of a paraganglioma.

\section{Discussion}

Carney's syndrome consists of the concomitant or successive occurrence of a combination of three tumours: gastric leiomyosarcoma, pulmonary chondroma and cate- cholamine-secreting paraganglioma. The syndrome has been incomplete in $74 \%$ of reported cases, with only two components being present $[1-10]$. The aetiology is unknown as these tumours do not share a common embryological origin, and no familial or genetic basis has been found. Indeed, a patient with Carney's syndrome has been described who had an unaffected identical twin [2]. The syndrome characteristically affects young females $(88 \%$ of cases have been female, with an average age of $18 \mathrm{yrs}$ ), but there is no evidence of these tumours being hormonally driven, and oestrogen receptors were not present in the chondromas of the patient studied.

Recognition of the other components of the syndrome is important in patients presenting with one of these rare tumours, and exclusion of a catecholamine-secreting paraganglioma is essential before undertaking surgery. The gastric leiomyosarcomas arise in the submucosa but often ulcerate into the gastric mucosa, typically presenting with haemorrhage and anaemia [2]. These are malignant tumours requiring full excision. When metastases occur, they often follow an indolent course emerging many years after gastrectomy [5]. The paragangliomas are the least common component of the syndrome. They usually secrete catecholamines and they may undergo malignant change. MIBG scintigraphy may be useful in detecting occult functioning paragangliomas [10].

Pulmonary chondromas have occurred in 36 of 42 reported cases of Carney's syndrome. In 11 cases the chondromas have been part of a complete triad of tumours, and in 25 cases they have occurred with a gastric leiomyosarcoma [1-10]. Typically, there is a long interval between diagnosis of the different components of the syndrome. The chondromas have antedated recognition of the leiomyosarcoma by as much as 17 yrs in five cases, were recognized at the same time in eight, and were found up to 22 yrs later in 23 cases. They are often multiple and have been bilateral in $33 \%$ of cases. They are often misdiagnosed as metastases from a previous leiomyosarcoma, and in one reported case leiomyosarcoma lung metastases coincided with pulmonary chondromas [8]. Calcification is a characteristic feature of the chondromas, but is often only apparent on CT and is not present in all cases [3]. In many cases, the benign nature of the chondromas has only been recognized after surgical resection, but with better recognition of the syndrome these lesions are often managed conservatively and kept under surveillance rather than resected. Where surgical resection is undertaken, enucleation of the chondroma is usually possible and conservation of lung tissue is important since further chondromas may develop many years later.

In most patients, the chondromas have been incidental findings on a chest radiograph and have not been associated with symptoms, but their natural history is uncertain. In some cases, they have grown slowly without giving rise to complications over a follow-up period of as long as 30 yrs [5]. In two cases, the chondromas have caused narrowing of airways with distal infection, but the development of a lung abscess, as in the present patient, has not previously been reported $[6,7]$.

\section{References}

1. Carney JA, Sheps SG, Go VLW, Gordon H. The triad of gastric leiomyosarcoma, functioning extra-adrenal 
paraganglioma and pulmonary chondroma. $N$ Engl J Med 1977; 296: 1517-1518.

2. Carney JA. The triad of gastric epithelioid leiomyosarcoma, pulmonary chondroma and functioning extra-adrenal paraganglioma: a five year review. Medicine 1983; 62: 159-169.

3. Beigelman C, Perez T, Remy-Jardin M, Ribet M, Remy J. La triade de Carney: l'imagerie dans le diagnostic et la surveillance. Rev Im Med 1990; 2: 171-177.

4. Barcena R, Erdozain JC, San Roman AL, Garcia M, Boixeda D, Perez FA. Triada de Carney: breve revision a proposito de un caso. Rev Clin Esp 1992; 190: 410-412.

5. Evans RA, Salisbury JR, Gimson A, Mitchell MJ. Case report: indolent gastric leiomyosarcoma in Carney's triad. Clin Radiol 1990; 421: 437-439.

6. Lacquet LK, Moulijn AC, Jongerius CM, Limburg M,
Rensing JB. Intrathoracic chemodectoma with multiple localisations. Thorax 1977; 32: 203-209.

7. Mazas-Artasona L, Romeo M, Felices R, et al. Gastrooesophageal leiomyoblastomas and multiple pulmonary chondromas: an incomplete variant of Carney's triad. $\mathrm{Br} \mathrm{J}$ Radiol 1988; 61: 1181-1184.

8. Chahinian AP, Kirschner PA, Dikman SH, Rammos KS, Holland JF. Pulmonary metastatic leiomyosarcoma coexisting with pulmonary chondroma in Carney's triad. Arch Intern Med 1983; 143: 1462-1464.

9. Schmutz GR, Fisch-Ponsot C, Sylvestre J. Carney synd rome: radiologic features. Can Assoc Radiol J 1994; 45: 148-150.

10. Lancha C, Diez L, Mitjavila M, Dolores R, Crespo A. A case of complete Carney's syndrome. Clin Nucl Med 1994; 19: 1008-1011. 